\title{
Research across the disciplines: a road map for quality criteria in empirical ethics research
}

\author{
Marcel Mertz ${ }^{1,2}$, Julia Inthorn ${ }^{3}$, Günter Renz ${ }^{4}$, Lillian Geza Rothenberger ${ }^{5}$, Sabine Salloch ${ }^{6}$, Jan Schildmann ${ }^{6}$, \\ Sabine Wöhlke ${ }^{3}$ and Silke Schicktanz ${ }^{3^{*}}$
}

\begin{abstract}
Background: Research in the field of Empirical Ethics (EE) uses a broad variety of empirical methodologies, such as surveys, interviews and observation, developed in disciplines such as sociology, anthropology, and psychology. Whereas these empirical disciplines see themselves as purely descriptive, EE also aims at normative reflection. Currently there is literature about the quality of empirical research in ethics, but little or no reflection on specific methodological aspects that must be considered when conducting interdisciplinary empirical ethics. Furthermore, poor methodology in an EE study results in misleading ethical analyses, evaluations or recommendations. This not only deprives the study of scientific and social value, but also risks ethical misjudgement.

Discussion: While empirical and normative-ethical research projects have quality criteria in their own right, we focus on the specific quality criteria for EE research. We develop a tentative list of quality criteria - a "road map" - tailored to interdisciplinary research in $\mathrm{EE}$, to guide assessments of research quality. These quality criteria fall into the categories of primary research question, theoretical framework and methods, relevance, interdisciplinary research practice and research ethics and scientific ethos.

Summary: EE research is an important and innovative development in bioethics. However, a lack of standards has led to concerns about and even rejection of EE by various scholars. Our suggested orientation list of criteria, presented in the form of reflective questions, cannot be considered definitive, but serves as a tool to provoke systematic reflection during the planning and composition of an EE research study. These criteria need to be tested in different EE research settings and further refined.
\end{abstract}

Keywords: Empirical ethics, Evidence-based ethics, Empirical methodology, Applied bioethics, Interdisciplinarity, Methodology, Quality criteria

\section{Background $^{\text {a }}$}

\section{Empirical ethics}

For roughly two decades there have been debates in bioethics about the question of how to address the challenge of best practice in interdisciplinary methodology. Empirical research in bioethics, principally using the methods of social sciences $[1,2]^{\mathrm{b}}$, has considerably increased during this period (e.g. [3]).

Generally speaking, this debate comes under the label of what is known as "empirical ethics" (abbreviated "EE", e.g. [4-8]); some authors prefer to talk about "empirically informed ethics" or sometimes "evidence-based ethics" (e.g.

\footnotetext{
*Correspondence: silke.schicktanz@medizin.uni-goettingen.de

${ }^{3}$ Department of Medical Ethics and History of Medicine, University Medical

Center Göttingen, Humboldtallee 36, D-37073 Göttingen, Germany

Full list of author information is available at the end of the article
}

[9-13]). This field calls for more empirical research, mainly from sociology, psychology or anthropology, and/or more consideration of empirical research results in normative bioethics ${ }^{c}$. Whereas empirical disciplines aim to be purely descriptive, however, EE has a strong normative objective: empirical research in EE is not an end in itself, but a required step towards a normative conclusion or statement with regard to empirical analysis, leading to a combination of empirical research with ethical analysis and argument.

\section{Research problem}

The widespread use of EE highlights the importance question above: what is the best practice for applying empirical methodologies in such an interdisciplinary setting? This interdisciplinary challenge is still not solved, and proponents of EE can self-critically assume that the

\section{Biomed Central}


quality of EE studies is often unsatisfactory. This problem can be tackled by two strategies: either focusing only on one particular methodology, or trying to establish standards for 'good' EE research. The advantage of the latter is obvious: methodologies are highly dependent on theoretical assumptions, and there is no such thing as one true theory, neither in empirical research nor in ethics. It therefore seems most appropriate to focus on best practice instead of perfecting one particular methodology in EE.

The lack of standards for assessing and safeguarding quality is not only a problem for scientific quality per se, but also an ethical problem: poor methodology in EE may give rise to misleading ethical analyses, evaluations or recommendations ${ }^{\mathrm{c}}$, not only depriving the study of scientific and social value, but also risking ethical misjudgement. Improving the quality of EE is therefore an ethical necessity in itself.

\section{Aims \& premises}

This article aims to provide a "road map" (see below) to assist researchers in conducting EE research, and also to initiate a more focused debate within bioethics about how to improve the quality of EE research. Our contribution should be understood primarily as a heuristic approach. As the discussion on quality criteria for EE research is rather new and touches on a number of complex topics within interdisciplinary research we would see our article as a first and provisional suggestion in this respect. We will discuss four domains of quality criteria and provide a tentative list of questions to be considered by researchers when engaging in EE research. Each formal quality criterion will therefore be guided by practical questions which illustrate its reflective and methodological purpose.

In this paper we will focus mainly on providing and discussing the abstract criteria, but will refrain from citing detailed examples for each criterion because of length limitations. While different application fields for quality criteria can be imagined (such as journal peer review, assessment of research proposals, or the planning of individual research projects), it should be noted that the criteria we present are only designed for guiding EE research (and, partially and indirectly, for reporting on it, since the reported study is what peer reviewers and readers of scientific literature ultimately see).

We start from the premise - supported by our own research, and corroborated by several authors in the debate e.g. $[6,8,14-18]$ - that empirical research is vital for the vast majority of normative ethical research. Here we focus on "applied ethics", that is, research concerning analyses, evaluations and recommendations in ethically sensitive fields such as medicine and clinical research, genetics and neuroscience, and also economics and the media.

As far as empirical research is concerned, we limit our claims here to socio-empirical research, i.e. studies based on methodologies from the social sciences. As to the normative-ethical aspect of EE research, we primarily refer to normative-ethical research based on philosophical methods. While theological methods are also important and valuable, we did not assess them in the context of this work.

\section{Approach}

\section{Definition of empirical ethics research}

As a descriptive definition of EE could not claim to define "empirical ethics" for all instances in which this term is used for this, (see e.g. $[11,15,19]$ ) we will confine ourselves to a stipulative definition covering the various ways of conducting EE research (e.g. [6,14,17,20,21]).

EE research, as we understand it, is normatively oriented bioethical or medical ethical research that directly integrates empirical research ${ }^{\mathrm{e}}$. Key elements of this kind of study are therefore that it encompasses (i) empirical research as well as (ii) normative argument or analysis, and (iii) attempts to integrate them in such a way that knowledge is produced which would not have been possible without combining them. Concerning (iii), we proceed on the assumption that descriptive and normative statements can and should be analytically distinguished from each other in order to evaluate their validity [22-24]. Some proponents of EE, e.g. those taking a phenomenological or hermeneutical approach (e.g. [7,25-27]), would assume that descriptive and normative statements are inevitably inseparable and indistinguishable. However, in the context of the current article, we exclude from our analysis approaches to EE research which are mainly hermeneutically or historically oriented. We believe that they can fruitfully contribute to EE research, but these approaches are in need of specific quality criteria that go beyond the scope of this paper. Nonetheless, the development of quality criteria or best practice standards might also be relevant for these approaches.

The above-mentioned integration of empirical research and a normative-ethical argument makes interdisciplinary work inevitable. It implies collaboration between researchers trained in different fields and methodologies. While it is theoretically possible for interdisciplinary research to be carried out by a single researcher skilled in more than one academic field, most EE research will benefit from interdisciplinary research teams (e.g. [8]). This is because the skills needed for applying both sound empirical research methods and thorough normative analysis and argument are seldom possessed by a single researcher.

Working in teams also offers the opportunity to overcome methodological biases, penchants for particular research approaches and intellectual myopia in terms of background assumptions. For example, in qualitative research (e.g. interviews, observations), intersubjective exchange during the interpretation process is a necessary 
precondition for enhancing the validity of the results. It also seems unlikely, on the basis of the criteria we are about to present, that such interdisciplinary (team-) work can be done (fully) independent of other team members, based on a strict division of labour between empirical researchers and ethicists. For all these reasons, in our further analysis we proceed on the assumption that EE research should best be carried out in an interdisciplinary research team.

\section{"Road map" analogy}

We propose to use the analogy of a "road map" in order to structure the different criteria in our paper, applying the metaphor of moving through a (not yet familiar) landscape for the conduct of EE research. According to this metaphor, the following criteria can be understood as "landmarks", indicating what paths to take, how fast to go, and where to expect a rocky road or a dead end.

\section{Mapping landmarks of quality and drafting a road map}

To survey specific "landmarks" of quality in EE research, and to draft a corresponding "road map", our procedure consists of the following main steps (Figure 1 Search and analysis strategy, provides a graphical overview of the search and analysis strategy the working groups used during the project):

(i) to analyse selected empirical quantitative and qualitative studies as well as theoretical ethics studies about living organ donation ("bottom-up-strategy") regarding their use of empirical data and ethical concepts, and if they reflected upon that relationship;

(ii) to study, present and critically discuss already established quality criteria for each of the following three branches of relevant criteria, viz. a) empirical/ social science research, b) philosophical/ normative-ethical research, and c) EE research ("top-down-strategy");

(iii) to consider, present and critically discuss research ethics criteria for each of the three branches, in the light of our experience in EE research and knowledge of the EE debate;

(iv) to develop a consensus among the authors;

(v) to refine the different branches and reduce complexity for publication; and

(vi) to draft a tentative checklist of questions which operationalises criteria pertinent to EE research.

Our search and analysis strategy included first (i) a bottom-up analysis of 10 publications, dealing explicitly and/or implicitly with ethical and empirical issues of living organ donation. This field was used as a focused case study to allow a comparison of quantitative $(n=3$ [28-30]) as well as qualitative ( $\mathrm{n}=3$ [31-33]) empirical studies and theoretical ethics publications $(n=4$ [34-37]).

This bottom-up detailed analysis revealed that firstly, the relevance of empirical data for ethical analysis is often not made explicit, secondly, empirical studies tend to be

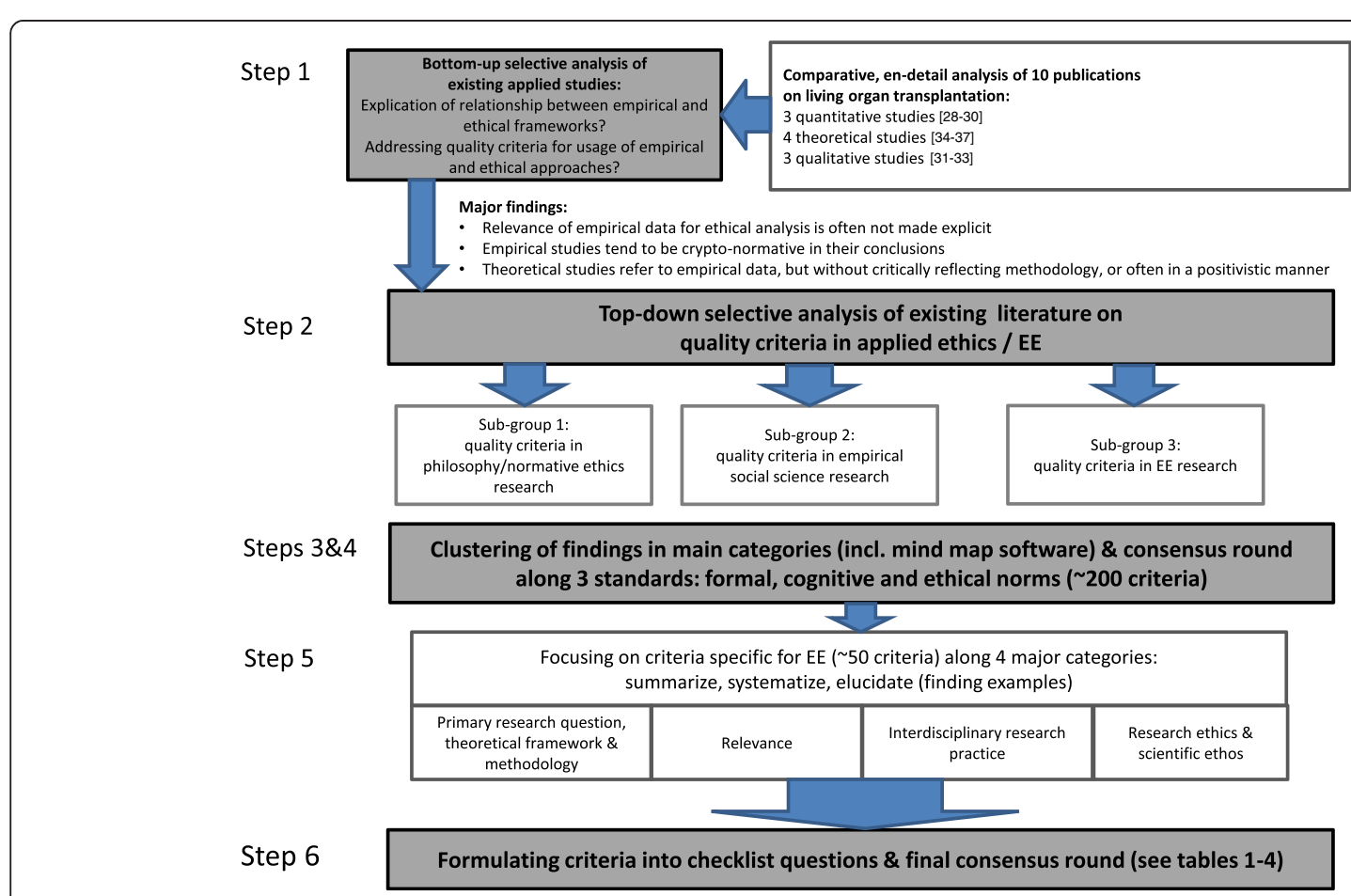

Figure 1 Search and analysis strategy. 
crypto-normative in their conclusions ("crypto-normative" for us implies that implicit evaluations and ethical conclusions are made, but the evaluative step is not explicated), and thirdly, theoretical studies often refer to empirical data, but rarely critically reflect the empirical methodology, or often tend to apply empirical data in a positivistic manner.

For step (ii), we applied a more top-down strategy by summarising existing literature in quality criteria in the three relevant fields: empirical research in social sciences, philosophy/normative ethics research, and EE research. Thus, we composed three subgroups in our Empirical Ethics Working Group (comprising about 13 active members at that time; see endnote (i) for further information about the working group). Each group conducted a review of the methodological literature in the relevant area. We also included explicit recommendations for quality research drafted by scholarly societies (e.g. of psychology or sociology).

Literature was searched with a narrative/selective search strategy (see e.g. [38]). This strategy was developed due to difficulties and inappropriate results when trying a systematic literature search by using specific search terms, given the interdisciplinary nature of our topic. As a consequence, we decided to broaden our approach by using literature found via PubMed, Philpapers and Google Scholar, via manual search of scientific journals, as well as via expert opinions generated from the members of our working group and their connections to the respective scientific community.

The subgroup of trained philosophers (MM, with nonauthors JD and UM; see Acknowledgments) analysing the criteria within philosophy often had to extract informal and implicitly given criteria (apart from criteria directly related to standards of argument, e.g. logic). The principal subcategories of criteria for philosophical, normativeethical research are the criteria of good argument (as discussed in informal and formal logic (see e.g. [39,40])), the use of specific philosophical methods (theories, approaches) with their respective quality criteria (e.g. [41]), and criteria of good ethical judgement and/or decisionmaking (as discussed in models and methods of decisionmaking (e.g. [42]) (see Figure 2, Specific criteria of quality).

The subgroup on quality criteria for empirical research in social sciences (LGR, GR) had to differentiate the literature search of journals and monographs into general criteria (such as adequacy of the research process, transparency, good scientific and ethical conduct) and specific criteria for quantitative methods (e.g. [43]), qualitative methods (e.g. [44-48]) or mixed-methods approaches (e.g. [49-51]) (see Figure 2).

The subgroup working on quality criteria for EE research (JS, SaS) performed a selective literature review in relevant bioethics journals and books focusing on theoretical and methodological contributions to EE research. While a number of conceptual accounts to EE were identified, the issue of quality standards was only rarely addressed $[52,53]$. However, parts of the conceptual considerations as identified in the literature could be translated into criteria relevant to EE research [54,55]. In addition, the researchers drew from current EE research addressing 'end of life issues' which is performed in an interdisciplinary research group of medical ethicists with a disciplinary background in philosophy, sociology and medicine.

Following these procedures, the findings of each subgroup were discussed within the whole working group. Our next step was to systematise the criteria identified by clustering them into main categories according to their field (empirical, philosophical, EE research), as well as into subcategories (e.g. different categories for qualitative and quantitative empirical research, or different categories for criteria related to logic/argumentation theory and philosophical approaches). The clustering was based on the literature search (inductive strategy), as well as on our own theoretical estimation of aspects relevant for assessing the quality of scientific work (deductive strategy). The summarising process was supported by mind mapping software to track modifications, deletions, additions or re-locations of criteria. The main and sub-categories in this mind map were generated either inductively on the basis of the literature or deductively by own reasoning against the backdrop of scientific experience and theoretical knowledge.

Finally, we derived three overarching standards of scientific research, which were subdivided into formal, cognitive and ethical norms (see below Three peaks that dominate the scenery) based especially on the philosophy of science. The actual quality criteria were then seen as specific expressions of these overarching standards.

In step (ii), issues concerning research ethics already found in the reviewed literature were added to the mind map as further criteria. Additional literature was also reviewed [56-59].

A consensus round was initiated for step (iii) where each criterion was again critically discussed with a view to identify possible redundancies. Consensus was reached with the results of the argumentation in the discussion, which was most often accompanied by a final, explicit request if there were any dissenting votes regarding the result. Active members of the working group who were not able to participate at the consensus round (about 3 out of 13 members) had the opportunity to show assent or dissent on the basis of the sent draft of the mind map; there was no crucial dissent that led to a substantial revision of the mind map.

The next step (iv) consisted of focusing on those criteria that were seen as only specific to and coherent with EE 


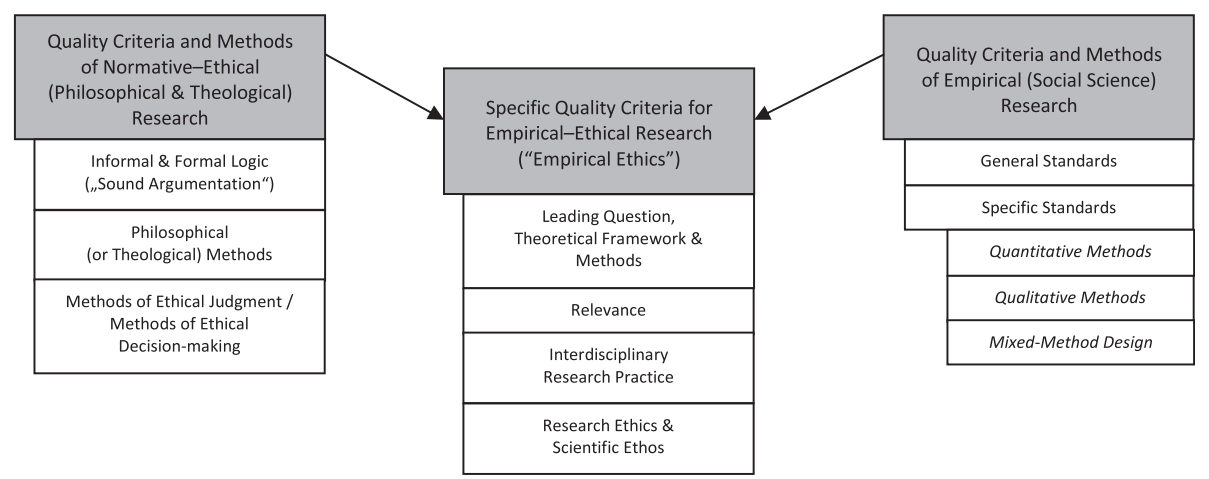

Figure 2 Specific criteria of quality.

research, excluding those relating to broadly empirical research in social sciences and philosophy. With this aim in mind, the working group agreed to divide specific EE criteria into four domains (see also Figure 1), effectively reducing the amount of criteria in the mind map of about 200 (all branches, research ethics included) to about 50. In these four domains, the formal and cognitive norms relevant to all kinds of scientific research were specified and adjusted to the particular field of EE research ("primary research question, theoretical framework \& methods" and "relevance"). Furthermore, the specific interdisciplinary nature of EE research was addressed ("interdisciplinary research practice"), and issues of research ethics which are pertinent to EE research ("research ethics \& scientific ethos") were considered.

As a result, four new subgroups were established that had to summarise, systematise and elucidate the according criteria on the basis of the already found literature of the three aforementioned subgroups, as well as propose additional criteria if found necessary. The members of these new subgroups also became the authors of the paper at hand and were assigned to the four domains as following: a) primary research question, theoretical framework \& methods (JI, SiS, SW); b) relevance (MM); c) interdisciplinary research practice (JS, SaS); and d) research ethics \& scientific ethos (LGR, GR).

This work also led to the last step (v), the drafting of a refined list which allows the "road map" below to be used as a checklist to guide EE research. For clarity, the criteria included in this list are presented in tabular form. These tables (see below) contain each criterion, operationalised into questions. We decided that it was heuristically more effective to ask questions rather than to consider statements, and to conceive these questions as a pragmatic aid to guide scholars and help them reflect on their own research. Nevertheless, the questions that operationalise criteria should not be understood as simple "yes/no" queries - instead they should function as reflective and critical questions designed to assess certain quality-related aspects of EE research. Each subgroup proposed their phrasing of the questions to the whole author group to achieve consensus on the final phrasing.

This checklist idea is not new. It is already well established in other research fields, e.g. in medicine for guideline recommendations (GRADE [60]; SIGN [61]), quantitative randomised medical trials (CONSORT [62]) and observational epidemiological trials (STROBE [63]), where they are used to check evidence and/or the quality of (the reporting of) trials. Although normative or especially ethical aspects are rarely explicitly mentioned in these checklists, they include implicit normative items such as asking for ethical approval, informed consent, funding or possible sources of bias. Critical appraisal is more and more coming up on the agenda of evidence based medicine ([64] see also [65]).

In analogy, we thought it necessary to render explicit ethical questions that are implicit in EE research. Looking for the best fitting form of presentation, our working group came to the consensus that we would try to adapt the checklist format, as we thought it will be most helpful in order to display the suggested criteria in a clear, feasible way.

\section{Discussion}

\section{The road map}

\section{An aerial view: spotting hills and valleys}

As is perhaps obvious, the first criteria that have to be considered are philosophical quality criteria, and social sciences quality criteria. This idea is already mentioned in the EE literature (e.g. $[54,66])$.

However, even if (ideally) one had knowledge of both sets of criteria, and had the relevant skills to apply them, distinctive features of the quality of EE research would still be missed. This is due to the interdisciplinarity of EE research, and specifically to the complexity that the necessary methodological combination of the two sets of criteria requires. This therefore goes far beyond the need for cooperation between disciplines. Additional criteria reflect, in particular, the combination of normative-ethical and empirical research. 
In the following, the "basic" philosophical and social science quality criteria will not again be summarised, as they have already been discussed in various contexts. We presuppose that quality work in EE research includes consideration of these already established criteria. Instead our major focus will be on criteria that are either (i) specific to EE research (i.e., not directly relevant to other ethical or social sciences research), or (ii) also useful in other research settings, but especially important for EE research.

\section{Three peaks that dominate the scenery: "good science" criteria}

There are three kinds of standards that dominate all research (including normative-ethical research, empirical research, and combinations of the two), as they are interconnected by norms which are generally concerned with "good" scholarship. They are based on a common-sense definition of what good science is: formal norms (scientific writing), cognitive norms (general methodology) and ethical norms (research ethics). All quality criteria ultimately derive their normative power from the same general norms and can thus be understood (more or less) as specific expressions of these norms.

\section{Looking for an interdisciplinary highway}

a) Setting up the road signs: designing a primary research question and selecting a theoretical framework and corresponding methods

EE research often faces the problem that the ethical and empirical aspects motivating our research are intertwined [66]. Special attention must therefore be paid to the design and development of the research question. The empirical and normative-ethical aspects of the research question have to be separated clearly without being split into two separate research approaches [22]; at the same time, the relationship between them has to be elucidated [23]. This reflective intermediate step is relevant because it shows why they are part of the same research, and cannot be dealt with sufficiently by two (or more) separate research projects. The inherent link between the parts should be considered on several levels: the theoretical assumptions [67], the relevance of empirical knowledge and data to the ethical question and vice versa [15], the chosen methodology $[66,68]$, the type of result/data envisaged, and the way the result can inform further EE research, both empirical and ethical [69] (see Table 1).

In theory-guided research, the research questions as well as the chosen methodology normally depend on a particular theoretical framework. The underlying assumptions and theoretical background of both the ethical and the empirical parts of the research should be made explicit and transparent $[22,67]$ (see Table 1). This includes theoretical work on different levels. Firstly, when combining empirical and ethical approaches, we need to reflect on the compatibility of the theories used in each part. The combination of two theoretical approaches needs to be consistent. For example, the empirical discourse analysis of communication structures cannot simply be transformed into ethical questions of individual responsibility for decisions. A more appropriate theoretical ethical approach would be one that ascribes a high level of normative relevance to communication and social interrelations. An analysis of the core concepts of the theoretical approaches makes it possible to test whether these approaches are compatible [73]. These core concepts include ideas such as human agency, the relationship between social and individual levels of agency, concepts of causality, the relevance and concept of gender, to name just a few examples [71,74].

Theoretical compatibility is also a point to consider when it comes to the question of how empirical and ethical research inform each other. Connected to this, the selection of both the empirical methods and the theoretical line of ethical argument (in short, the theoretical method) is crucial. Both methods need to be compatible with the combined theoretical framework of the research, but should also reflect how the results of each part can inform the other part $[66,68]$. For example - and this is far from being an exhaustive list -, discursive ethical approaches have strong links with argumentative, discursive methods of surveying opinion, while liberal-utilitarian ethical approaches tend to accept opinion polls and quantitative surveys. Critical reflection on the chosen methods and on their limitations for the combined argumentation is a must for all EE.

b) "Driving only when necessary": demonstrating relevance

Even if an EE study is sufficiently transparent with regard to its primary research question and methods, it can still be unnecessary, or more specifically, not valuable [22]. From an epistemic, ethical and even economic point of view (due to limited research resources), one can claim that an interdisciplinary approach should only be favoured if it is likely to lead to new insights, or to broader or more nuanced insights than those gained from intradisciplinary research. One should also bear in mind that it is ethically problematic to expose research participants (e.g. patients as interviewees) to stress if the research has low relevance (see also section $\mathrm{d}$ ).

Relevance should be understood on two levels, as epistemic relevance on the one hand and societal relevance on the other. Scholars conducting EE research must be able to demonstrate the value of their planned project in at least one sense, and ideally in both (see Table 2).

The main issue regarding epistemic relevance (e.g. $[56-58,79])$ is whether the study makes a contribution to academic ethics, for example by adding new knowledge (e.g. developing a sound ethical argumentation for the topic in question), contributing to an ongoing controversy 
Reflection on the relationship between empirical and ethical-normative/ethical-descriptive research questions (even if the ethical motivation is more prominent than the ethical research question)

Development/use of theoretical frameworks:

Use of empirical and ethical methods and their relationship to the theoretical framework:
- Can an explicit distinction be made between the empirical and ethical research questions? (e.g. a distinction between interviewing patients about their wishes and the ethical weight given to patient autonomy) [22,23]

- How dependent is the empirical research question on particular ethical background assumptions? (e.g. justification for the selection of a target group for a questionnaire: why do we think their opinion is ethically relevant?) [70]

- How is the ethical research question dependent on empirical or socio-theoretical background assumptions? (e.g. ethical considerations of vulnerability of a particular group such as pregnant women: what are the underlying anthropological or psychological considerations? Are there any hidden gender-related stereotypes?) [66]

- What are the explicit and implicit research interests and motivations of the EE researchers? (e.g. is research with dying patients motivated by curiosity or the moral attempt to empower them? Is the researcher motivated to identify possible conflicts of interest or might the research serve mainly to produce more social acceptance of a technology?) $[14,69]$

- What kind of epistemic research interest motivates the researcher to combine ethical and empirical research? (e.g. explaining whether the aim is the evaluation of established ethical practice, or of measures taken to improve ethical practice; or whether the aim is ethical theory-building, norm-construction, or legitimization/critique or a particular practice) [15]

- How can a theoretical framework be developed; what are the main limitations of the chosen theoretical framework? (e.g. premises and limitations of a principle of autonomy, when analysing macro-social interactions) [22], see contributions in [67]

- Were potential ambiguities of central concepts considered within the theoretical framework? (e.g. to which extent is the concept of 'identity' used differently in current philosophy and in sociology when wanting to analyse the discourse of identity changes by neuroenhancement empirically and its ethical implications) [71,72]

- How does the chosen medico-theoretical framework (e.g. concept of disease/health) fit into the ethical-normative framework? (e.g. does a science-positivistic concept of disease fit into a Kantian or hermeneutic approach of ethics?) [73]

- How does the chosen sociological-, cultural- or philosophical framework (e.g. concept of personal identity) fit into an ethical normative framework (e.g. approach to a cosmopolitical ethics of justice?) [74]

- Are the chosen empirical methods compatible with the combined theoretical framework? (e.g. are interviews with doctors as experts compatible with a liberal, autonomy-driven approach that claims to empower patients?)

- What is the advantage of the chosen method in comparison to other available methods? (e.g. why and when to choose a deductive approach in applied ethics to assess ethical problems of a new technology and not an inductive, or hermeneutic one?) $[66,68]$

- Are the chosen methodological approaches appropriate for the envisaged combined research question? (e.g. does the empirical method of interviewing parents generate results relevant for the ethical question of whether parents should be allowed to influence the genetic make-up of their children?) (e.g. providing a new perspective), or criticizing established positions on a theoretical or applied level. In other words, it needs to be clear what knowledge gains the research will provide in terms of the development, modification or application of theory.

Another way to ensure scientific relevance, especially in EE research, is to develop or refine scientific methods. Potential for innovation (e.g. constructing a new theory or new instruments for ethical decision-making) should also be regarded as part of epistemic relevance. If there is a contribution to other disciplines (e.g. to social science debates on agency or social dependency), this also fulfils the criterion of epistemic relevance. Finally, the target group of a study, e.g. the future beneficiaries of the results and conclusions of this particular EE research, should be clearly stated. This gives guidance for research planning, and for the analysis of the results.

As far as societal or practical relevance (e.g. $[58,59,79])$ is concerned, EE research should be able to show what it contributes to the improvement of ethical praxis. As much ethics research is funded by public money, it might even be argued that there is a moral obligation to generate not only scientifically valuable knowledge, but also knowledge that benefits society or certain groups within it, e.g. specific vulnerable group. This assumption relies on a normative understanding of ethics as a discipline aimed at providing 
Contribution to (scholarly) ethics (epistemic/scientific relevance):
- Will the study possibly produce knowledge that could not be generated by relying on traditional disciplinary methodologies? (e.g. overcoming too separated empirical research and separate philosophical discussion) $[15,22]$

- Does the study aim to increase our knowledge, and if so, with regard to what? (e.g. does the study contribute to a balance between theoretically generated norms and empirically found norms? E.g. Does it revise/improve the impact of ethical guidelines?) $[56-58,78]$

- Does the study aim to give input on an ongoing controversy, or does it provide a new perspective on it? (e.g. clarifying if relatives are able to give substitute judgment for incapacitated patients or not, or e.g. if post-trial access should be compelling on the basis of new evidence of consequences when post-trial access is not given etc.) [16], partly [76]

- Does the study aim to offer substantial arguments for or criticism of established ethical positions? (e.g. is a contribution to theory modification or to a refinement of the application of a theory expected? Are descriptive presuppositions of an ethical position, such as anthropological, sociological or psychological assumptions, criticised?) $[1,16,66]$

- Does the study aim to contribute to the development or refinement of scientific methods, especially methods of EE research, and if so, how? (e.g. pilot testing of a jointly developed research instrument, identifying the need of developing new or refined forms of interactions between researchers) $[6,58]$

- Does the study aim to offer potential for innovation, and if so, what kind of innovation? (e.g. is it a contribution to theory-building expected? Will the study generate new instruments for ethical decision-making?) [6,77]

- Does the study aim to contribute to another scientific and/or ethical discourse? (e.g. does it contribute to social sciences discourses?) [partly [1]

- Does the study clearly states to whom it is addressed, and who will benefit from its results? (e.g. are the addresses and/or beneficiaries physicians, nurses, social scientists, ethicists or especially empirical ethicists? Are policy-makers or persons in a management position addressed? [58]

- Does the study aim to improve ethical decision-making? (e.g. will it produce evidence that was absent, or will it give guidance regarding the specification of accepted norms or regarding the interpretation of institutional or legal rules?) $[6,14,75]$, partly [17]

- Does the study aim to raise awareness (among actors, institutions or society) of particular ethical problems? (e.g. does the study identify new ethical problems, or does it highlight specific aspects of a known ethical problem that was not yet addressed sufficiently in practice?) $[20,78]$

- Does the study aim to lead to a shift in structures and/or decision-making processes (in relevant institutions)? (e.g. establishing new guidelines or building new forms of committees for ethical review) [77], partly [23]

- Does the study aim to establish minimum ethical standards (in relevant institutions or professions)? (e.g. creating new informed consent procedures for specific patient groups?)

- Does the study aim to contribute to or stimulate public debate? (e.g. about physician-assisted suicide, rationing in health care, public health funds etc.)

- Does the study aim to contribute to or stimulate a process of legislation? (e.g. proposing alteration of legal norms)

- Does the study aim to articulate the need for reforms (in a certain institution or system of society)? (e.g. by evaluating current practices.) [6]

- Does the study aim to articulate new ethically pertinent ecological or economic problems? (e.g. costs related to a broad implementation of the use of social robots in elderly care) [16] orientation knowledge, which is needed to detect problems or to indirectly or directly improve praxis. So scholars should try to demonstrate the societal/practical relevance of their EE research whenever feasible.

Examples of this kind of relevance could be improvements to ethical decision-making (e.g. an empirically tested model of ethical decision-making), raising awareness of ethical problems and challenges (e.g. showing that without regulated antimicrobial stewardship, there is a high risk of antibiotics increasingly losing their effectiveness), a shift in structures and decision-making processes (e.g. not asking relatives what they want, but what the patient would have wanted), or the establishment of minimum ethical standards in the institutions or professions related to the praxis under consideration (e.g. formulation and implementation of guidelines). Furthermore, societal relevance is present when the study initiates or simply provides a stimulus for public debate, or leads to/assists the process of legislation. Articulating a need for reforms or new ethically pertinent ecological or economic problems - or articulating existing problems in a new, enlightening way - is also of societal relevance (e.g. [80]).

We are not arguing that all EE research has to demonstrate societal or practical relevance. EE research can be 
relevant even if it is only relevant for scientific/scholarly reasons. Nonetheless, as stated above, since ethical research seems (to us) to be ultimately guided by a practical interest in ameliorating (some) social practices, scholars need to think about potential societal relevance when planning or evaluating their own EE research (compare also [24]).

c) "Enabling car sharing": guaranteeing interdisciplinary research practice

Quality criteria for interdisciplinary cooperation in EE research encompass different stages of the research process, including drafting, data gathering, data analysis and conclusions [36,37]. For the different stages, the following points are of particular importance (see Table 3).

In the planning stage of an EE study, the reflection on adequate forms of interdisciplinary collaboration should include consideration of not only its potential benefits, but also its limitations. Limitations are often the result of different professional jargons and terms [3]. It is therefore advisable to clarify terminology at the beginning of the collaboration. Furthermore, a clear distribution of competences and responsibilities within the research team is needed. A further challenge in the planning of an EE study is posed by the literature research, which has to consider journals, books, and databases from diverse fields [84]. During data gathering, it is important to reflect the potential bias produced by normative or descriptive assumptions [54]. One should also be aware of possible biases when selecting published empirical studies (e.g. [85]).

During data analysis, researchers should explicitly discuss the relevance of ethical theories, concepts, or standpoints for the empirical data analysis, as well as possible reductionist tendencies associated with the

Table 3 Criteria related to interdisciplinary research practice

Research drafting:

Data gathering:

Data analysis and conclusions:
- What form of interdisciplinary collaboration serves the needs of an EE study? (e.g. how strong and how often should collaborators interact? Is it necessary to have face-to-face-meetings? Who has to be involved in which step of the research? Is there reflection on the potentials and the limitations of the kind of collaboration?) [18]

- How can the participating researchers be adequately selected? (e.g. Which disciplines/methods are actually needed?)

- How can an appropriate task schedule be developed? (e.g. at which point in time is empirical data to be gathered)

- Which agreements must be reached with regard to interdisciplinary communication? (e.g. consideration of terms used, explanation of professional jargon and development of a "common language") [3]

- How can competencies and responsibilities be reasonably distributed within the research team? (e.g. despite their varying competencies, will all the interdisciplinary researchers remain actively involved in the research process? Who is accountable for what?)

- How can research questions be developed jointly? (e.g. regarding different interests and disciplinary perspectives, or regarding the goal of the study)

- How can the literature search be carried out? (e.g. having to acknowledge empirical-ethical studies from one's own thematic field as well as to acknowledge both empirical and ethical work from different disciplines in diverse types of publication)

- How is the joint development or modification of a research instrument carried out? (e.g. Is there a process that allows for dissent and argument in developing or modifying a research instrument?)

- Is there normative-ethical reflection on the empirical research process? (e.g. can implicit normativity be revealed that is related to a theoretical background ("social constructivism")?)

- Is there a mutually critical appraisal by normative and empirical sciences with regard to data gathering? (e.g. what constitutes "good" data for the EE study) [54]

- How do normative and empirical aspects interrelate with regard to analysis and deliberation?

- Is the analysis of the empirical data influenced by normative theories, concepts, or standpoints? (e.g. by a specific account of patient autonomy)

- Is the normative deliberation influenced by the requirements of the empirical data analysis? (e.g. by standardization of data) [81]

- How do normative and empirical aspects interrelate with regard to the study's conclusions?

- Are the ethical conclusions actually linked with normative premises? (e.g. avoiding an is/ought fallacy) $[16,23]$

- Are the empirical conclusions supported by the data, or is there a bias in the empirical results based on the normative conclusions? (e.g. avoiding a normativist fallacy or "wishful thinking", deducing broad conclusions from fine-grained data, under- or overrating of empirical data, ignoring of empirical evidence that would criticize normative conclusions etc.) $[82,83]$

- Is there a critical evaluation of the results? (e.g. addressing methodological critique with regard to interdisciplinary cooperation, or indication of limitations) 
requirements of particular methods, e.g. the standardization of question wording and statistical analysis in quantitative surveys [81]. A final crucial question is how much the empirical results contribute to the normative judgement $[16,24]$. Do they help to "justify" a particular norm, and if so, based on which ethical theoretical consideration? Or do they have an impact on the level of practical application, when public acceptance seems crucial if a rule is to be applied in a particular way? It is also desirable to consider whether the interpretation of the empirical data (e.g. approval or criticism of a particular group's view) was led by a particular ethical view [82].

d) "Driving responsibly": observing research ethics \& scientific ethos

Of course EE research is liable to general principles of research ethics in general and bioethics in particular. Important topics are avoiding harm to the participants $[86,87]$, confidentiality and data safety $[86,88,89]$, informed consent $[86,90,91]$, management of research data $[89,92]$.

Our discussions within our broader research group revealed, that in addition to that some aspects are of special importance in the field of EE research:

In an interdisciplinary setting where researchers can have different institutional backgrounds and differ in the personal motivations for their research, potentially competing interests should be disclosed and critically discussed. There should be explicit reflection about the interdisciplinary setting and the division of labour (see e.g. [93]). This, we think, must include a readiness to critically reflect upon a possible inclination to design the empirical part of the research in such a way that the results may favour the researcher's own ethical position. For example, one should ask: am I especially critical or joyful when it comes to this issue? Do I tend to exaggerate the issue in my research questions? Which results of the empirical research would I predict and which would I wish to see? Here the interdisciplinary context offers an excellent opportunity for an open discourse (see Table 4).

With regard to so-called informed consent, different standards may obtain in different disciplines such as medicine $[94,95]$, psychology $[96,97]$ or social sciences [98-100]. However, we think that it is the task of the interdisciplinary research team to openly and ethically consider the possibilities and to choose the most appropriate format - which may exceed the legal standard. Regardless of consent by the participants, the definitive ethical responsibility remains with the researcher - especially as the EE researcher may be faced with a confidence bonus granted by the research participants just because she/he is an ethicist (an "ethical misconception" analogous to the "therapeutic misconception" in some clinical research). It is the researcher's duty to deal with this bonus very carefully.

EE research can be misinterpreted by politicians and special interest groups. Therefore, we suggest that researchers should reflect on the following questions: have we ensured that the results cannot easily be misunderstood or misused? Might the EE study have unanticipated negative consequences that could be detected in advance and therefore avoided? Although it seems clear that we cannot anticipate every kind of negative consequences, the EE researcher may have a particular responsibility to carefully reflect on the outcomes of her/his own research beyond the short time frame of the study, since EE might have a strong influence on public policies, e.g. in health care or biopolitics.

\section{Limitations and conclusions Limitations}

We assume that it is theoretically acceptable to start from the analytical premise that there is genuine ethical research on one side and genuine empirical-descriptive research on the other, and that these have to be paired up with each other through interdisciplinary research practices. We reject, on the other hand, a stance that denies the need for, the possibility of, or the value of strong interdisciplinary collaboration between empirical and ethical research (e.g. being afraid of naturalistic fallacies) to gain a valid applied ethical conclusion ${ }^{\mathrm{f}}$.

Our research is strongly influenced by experience and in-depth analysis of current EE research in the context of Western bioethics and medical ethics. It does not encompass other possible epistemic approaches such as revealing "concealed" normativity in empirical research, or more institutional aspects of a combination of ethical and empirical disciplines. Our "road map" is therefore restricted to this field. Whether this "road map" can be of use in other ethical disciplines, such as economic/business ethics or ecological ethics, has to be explored elsewhere.

Because our literature search strategy was selective, there are of course limitations concerning the completeness of reviewed literature. There is a good case to believe that further criteria could be mentioned when including additional literature. But discussing quality criteria for EE research in a single short publication necessitates condensation and simplification; we therefore understand this paper as an attempt to encourage more intensive metaethical and methodological discussion within the EE field.

The proposed criteria in this paper need to be tested in EE research practice. It is likely that the deliberate use of these criteria to guide and report on individual research will lead to the refinement, addition or removal of some criteria.

\section{Conclusions}

EE is a highly interdisciplinary and dynamic research field with specific methodological aspects. Because of its genuinely interdisciplinary nature, a reflection on methodological quality is necessarily more complex than in 


\section{Table 4 Criteria related to research ethics \& scientific ethos}

\section{Competing interests:}

Informed consent:

Reporting results:

Consequences for the future:
- Which personal (e.g. cultural, philosophical, theological) presumptions concerning ethics may bias the EE research process significantly and how can they be adequately managed? (e.g. inclination to a emotivist meta-ethics, a neopositivist philosophy of science, a postmodernist account of society etc.) [42]

- Do different standards exist in the various disciplines involved, and if so, have they been critically and respectfully discussed among the EE research team to find the most appropriate ethical standard? (e.g. is waiving of consent allowed, is assent sufficient, how to establish informed consent in emotional difficult situations at the end of life etc.) [43-49]

- Is the EE research team aware of a possible confidence bonus, and have strategies been developed to deal with this phenomenon carefully? (e.g. making transparent which goals and which limitations the own study will have and informing research participants and partners accordingly)

- Is the EE research team aware of the (implicit) ethical impact of the way results are presented? (e.g. was the potential for stigmatization or discrimination considered when choosing the wording and emphasis of particular results?) [30], partly [50]

- Has the EE research team made sure that the way the results are presented reduces the potential for misinterpretation by third parties such as politicians and special interest groups? (e.g. by changing perspectives when re-reading results and revising the wording etc.)

- Has the risk-benefit ratio for the EE research project been discussed in terms of its possible consequences for the people/society of the (near/more distant) future? (e.g. does lay considerable burden on study participants for a relatively low practical or epistemic output?) [30]

- Has the research team overlooked any negative consequences that could be detected in advance and therefore avoided? (e.g. acknowledging non-scientific partners when publishing, the handling of emotional distress of participants in interview studies with sensible questions, supervision of researchers involved in asking sensible questions etc.) traditional intradisciplinary ethical or empirical research. However, contributions addressing the specific challenges of EE research are so far rare. We have therefore tried, in this article, to give an overview of basic criteria which have to be considered to arrive at EE studies of good scientific quality; they may also inform the assessment of research protocols or proposals. We assume that many of the suggested criteria are self-evident, perhaps even common-sense - but the important thing here is the argument that they should be used together as a whole.

However, our analysis also points out conflicts that may occur between different quality criteria, especially those concerning the empirical part of the research on the one hand and the ethical part on the other. While researchers may not always be able to overcome such conflicts, it is paramount to at least address these different requirements when publishing EE research and to defend the chosen approach in the light of this conflict.

\section{Summary}

We have argued that empirical research in EE is not an end in itself, but vital for reaching applied normative conclusions. As such EE research is usually interdisciplinary, engaging in sound EE research requires more than merely maintaining the quality of normative argument and empirical method.

Thus criteria for determining the quality of genuinely interdisciplinary aspects of EE research, methodological as well as ethical, are required. We have proposed several criteria of this kind under the headings Primary Research Question, Theoretical Framework and Methods, Relevance,
Interdisciplinary Research Practice and Research Ethics and Scientific Ethos. Although these criteria cannot (yet) be considered definitive, they provide a starting point for reflection on the topic. The criteria need to be tested in real EE research practice and evaluation, and are likely to require further refinement.

\section{Endnotes}

${ }^{a}$ The following paper has been jointly produced by core members of the Empirical Ethics Working Group (coordinator until the end of 2013: Prof. Dr Silke Schicktanz; current coordinators: Jan Schildmann and Marcel Mertz) of the German Academy for Ethics in Medicine (AEM; see http://www.aem-online.de). The working group was founded in 2007, with the objective of bringing together researchers interested in the challenges of empirical research in bioethics, and particularly its relevance to and connection with normative-ethical research. The working group became highly interdisciplinary, consisting of philosophers, theologians, medical ethicists, social scientists, physicians, and humanities scholars.

${ }^{b}$ Researchers in the field of EE use a broad variety of empirical research approaches, which overlap with the methods used in empirical disciplines such as the social sciences, psychology, ethnography and anthropology (see e.g. $[16,101])$.

${ }^{\mathrm{c}}$ Though sometimes results from empirical research in bioethics, without any normative conclusions, are also categorised under this label (see e.g. $[55,102,103]$ ).

${ }^{d}$ This is especially important for attempts to ethically improve clinical practice guidelines, ethical guidelines 
or clinical support services by relying on empirical data, as the situation concerning quality criteria is similarly unsatisfactory (e.g. [77,104]]).

${ }^{\mathrm{e}}$ Studies that explicitly rely on (vast) empirical research (results) for their ethical argumentation, but do not engage in empirical research themselves, should also be considered when discussing issues of quality in $\mathrm{EE}$ research. We decided, though, to focus here solely on EE studies that incorporate genuine empirical research.

${ }^{f}$ Though we do not think that EE research is generally burdened with the problem of avoiding the naturalistic fallacy, or that it usually illegitimately crosses the is/ought gap (see [23]).

\section{Abbreviation}

EE: Empirical ethics.

\section{Competing interests}

Financial competing interest: None to declare. Non-financial competing interest: All the authors of this paper are committed to EE research and will therefore not generally assess such efforts in a negative way. Moreover, they have all engaged in EE research and have an interest in pursuing such research further.

\section{Authors' contributions}

MM: drafted and revised the manuscript in general, drafted section "Driving only when necessary", coordinated the writing process, and finalised the manuscript. J: drafted section "Setting up the road signs", and revised the manuscript. GR: drafted section "Driving responsibly", made substantial contributions to limitations section, and revised the manuscript. LGR: drafted section "Driving responsibly", made substantial contributions to limitations section, and revised the manuscript. SaS: drafted section "Enabling car sharing", made substantial contributions to conclusions section, and revised the manuscript. JS: drafted section "Enabling car sharing", made substantial contributions to conclusions section, and revised the manuscript. SW: drafted section "Setting up the road signs", and revised the manuscript. SiS: drafted section "Setting up the road signs", revised and finalised the manuscript; initiated and coordinated the Empirical Ethics Working Group (until the end of 2013). All the authors were involved in the conception and design of the material presented, and read and approved the final manuscript.

\section{Acknowledgements}

We would like to express our thanks to other members of our working group who enriched our discussions substantially: Monika Bobbert, Ruth Denkhaus, Julia Dietrich (JD), Jochen Fehling, Uta Mueller (UM) and Danie Strech. We also thank both the reviewers for their insightful remarks.

\section{Author details}

'Institute for History of Medicine and Medical Ethics, Research Unit Ethics, University of Cologne, Herderstr. 54, D-50931 Cologne, Germany. ${ }^{2}$ Institute for Ethics, History and Philosophy of Medicine, Hannover Medical School, Carl-Neuberg-Str. 1, D-30625 Hannover, Germany. ${ }^{3}$ Department of Medical Ethics and History of Medicine, University Medical Center Göttingen, Humboldtallee 36, D-37073 Göttingen, Germany. ${ }^{4}$ Protestant Academy Bad Boll, Bad Boll, Akademieweg 11, D-73087 Bad Boll, Germany. ${ }^{5}$ Formerly at: Institute of Ethics and History in Medicine, Centre for Medicine, Society and Prevention, University of Tübingen, Gartenstr 47, D-72074 Tübingen, Germany. ${ }^{6}$ Institute for Medical Ethics and History of Medicine, NRW Junior Research Group "Medical Ethics at the End of Life: Norm and Empiricism", Ruhr University Bochum, Malakowturm, Markstr 258a, D-44799 Bochum, Germany.

Received: 16 April 2013 Accepted: 10 February 2014 Published: 1 March 2014

\section{References}

1. Haimes E: What can the social sciences contribute to the study of ethics? Theoretical, empirical and substantive considerations. Bioethics 2002, 16(2):89-113.

2. Hedgecoe AM: Critical bioethics: beyond the social science critique of applied ethics. Bioethics 2004, 18(2):120-143.

3. Borry P, Schotsmans P, Dierickx K: The birth of the empirical turn in bioethics. Bioethics 2005, 19(1):49-71.

4. Salloch S, Schildmann J, Vollmann J: Empirische Medizinethik: Eine Übersicht zu Begriff und Konzepten. In Empirische Medizinethik. Konzepte, Methoden und Ergebnisse. Edited by Vollmann J, Schildmann J. Münster: LIT Verlag; 2011:11-24

5. Hope T: Empirical medical ethics. J Med Ethics 1999, 25:219-220.

6. Molewijk B, Stiggelbout AM, Otten W, Dupuis HM, Kievit J: Empirical data and moral theory. A plea for integrated empirical ethics. Med Health Care Philos 2004, 7:55-69.

7. Widdershoven G, Van der Scheer L: Theory and methodology of empirical ethics: a pragmatic hermeneutic perspective. In Empirical ethics in psychiatry. Edited by Widdershoven G, McMillan J, Hope T, Van der Scheer L. New York: Oxford University Press; 2008:23-36.

8. McMillan J, Hope T: The possibility of empirical psychiatric ethics. In Empirical ethics in psychiatry. Edited by Widdershoven G, McMillan J, Hope T, Van der Scheer L. New York: Oxford University Press; 2008:9-22.

9. Tyson JE, Stoll BJ: Evidence-based ethics and the care and outcome of extremely premature infants. Clin Perinatol 2003, 30:363-387.

10. Strech D: Evidence-based ethics - What it should be and what it shouldn't. BMC Med Ethics 2008, 9:16

11. Mertz M: Zur Möglichkeit einer evidenzbasierten Klinischen Ethik. Philosophische Untersuchungen zur Verwendung von Empirie und Evidenz in der (Medizin-)Ethik. GRIN Verlag: München/Ravensburg; 2009.

12. Kalichman M: Evidence-Based Research Ethics. Am J Bioeth 2009, 9(67):85-87.

13. Salloch S: Evidenzbasierte Ethik"? - Über hypothetische und kategorische Handlungsnormen in der Medizin. Ethik Med 2012, 24:5-17.

14. Borry $P$, Schotsmans $P$, Dierickx $K$ : What is the role of empirical research in bioethical reflection and decision-making? An ethical analysis. Med Health Care Philos 2004, 7:41-53.

15. Musschenga AW: Empirical ethics, context-sensitivity, and contextualism. J Med Philos 2005, 30(5):467-490.

16. Sulmasy DP, Sugarman J: The Many Methods of Medical Ethics (Or, Thirteen Ways of Looking at a Blackbird). In Methods in Medical Ethics. 2nd edition. Edited by Sugarman J, Sulmasy DP. Washington D.C: Georgetown University Press; 2010:3-20.

17. Kon AA: The Role of Empirical Research in Bioethics. Am J Bioeth 2009, 9(6-7):59-65.

18. Birnbacher D: Ethics and social science: which kind of cooperation? Ethical Theory Moral Pract 1999, 2:319-336.

19. Schicktanz S, Schildmann J: Medizinethik und Empirie Standortbestimmungen eines spannungsreichen Verhältnisses. Ethik Med 2009, 21(3):183-186.

20. Ives J, Draper H: Appropriate methodologies for empirical bioethics: It's all relative. Bioethics 2009, 23(4):249-258.

21. Reiter-Theil $\mathrm{S}$ : What does empirical research contribute to medical ethics? A methodological discussion using exemplar studies. Camb Q Healthc Ethics 2012, 21(4):425-435.

22. Düwell M: Wofür braucht die Medizinethik empirische Methoden? Eine normativ-ethische Untersuchung. Ethik Med 2009, 21:201-211.

23. De Vries R, Gordijn B: Empirical ethics and its alleged meta-ethical fallacies. Bioethics 2009, 23(4):193-201.

24. Dunn M, Sheehan M, Hope T, Parker M: Towards Methodological Innovation in Empirical Ethics Research. Camb Q Healthc Ethics 2012, 21:466-480.

25. Lindseth A, Norberg A: A Phenomenological Hermeneutical Method for Researching Lived Experience. Scand J Caring Sci 2004, 18:145-153.

26. Ebbesen M, Pedersen $B$ : Using empirical research to formulate normative ethical principles in biomedicine. Med Health Care Philos 2007, 10:33-48.

27. Rehmann-Sutter C, Porz R, Scully JL: How to relate the empirical to the normative. Toward a phenomenologically informed hermeneutic approach to bioethics. Camb Q Healthc Ethics 2012, 21:436-447.

28. Strong RW: Living-donor liver transplantation: an overview. J Hepato-Biliary-Pancreat Surg 2006, 13(5):370-377. 
29. Decker O, Winter M, Brähler E, Beutel M: Between commodification and altruism: gender imbalance and attitudes towards organ donation. A representative survey of German. Journal of Gender studies 2006, 17(3):251-255

30. Schicktanz S, Rieger JW, Lüttenberg B: Geschlechterunterschiede bei der Lebendnierentransplantation: Ein Vergleich bei globalen, mitteleuropäischen und deutschen Daten und deren ethische Relevanz. Transplantationsmedizin 2006, 19:83-90.

31. Kranenburg LW, Richards M, Zuidema WC, Weimar W, Hilhorst MT, ljzermans JN, Passchier J, Busschbach JJ: Avoiding the issue: Patients' (non) communication with potential living kidney donors. Patient Educ Couns 2009, 74:39-44.

32. Gill $P$, Lowes $L$ : Gift exchange and organ donation: Donor and recipient experiences of live related kidney transplantation. Int J Nurs Stud 2008, 45:1607-1617.

33. Andersen $\mathrm{MH}$ : Follow-up interviews of 12 living kidney donors one year after open donor nephrectomy. Clin Transplant 2007, 21:702-709.

34. Truog R: The Ethics of Organ Donation by Living Donors. N Engl J Med 2005, 353:444-446

35. Eibach U: Organspende von Lebenden: Auch unter Freunden ein Akt der „Nächstenliebe"? Zeitschrift für Medizinische Ethik 1999, 45:217-231.

36. Paul N: Zu den Grenzen des Altruismus in der Lebendorganspende. In Ethik der Lebendorganspende. Edited by Rittner C, Paul N. Mainz: Akademie der Wissenschaften und der Literatur; 2005:205-215.

37. Gutmann T: Die Ethik der Lebendspende. In Organlebendspende in Europa. Edited by Gutmann T, Schroth U. Berlin: Springer; 2002:107-122.

38. Ressing $M$, Blettner $M$, Klug SJ: Systematic literature reviews and meta-analyses. Part 6 of a Series on Evaluation of Scientific Publications. Dtsch Arztebl Int 2009, 106(27):456-463.

39. Fogelin RJ, Sinnott-Armstrong W: Understanding Arguments. An Introduction to Informal Logic. Belmont, CA: Wadsworth; 2005

40. Toulmin SE: The Uses of Arguments. Cambridge: Cambridge University Press; 1993.

41. Wuchterl K: Methoden der Gegenwartsphilosophie. Stuttgart: Paul Haupt; 1999.

42. Dietrich J: Zur Methode ethischer Urteilsbildung in der Umweltethik. In Umweltkonflikte verstehen und bewerten: Ethische Urteilsbildung im Natur und Umweltschutz. Edited by Eser U, Mueller A. München: Oekom-Verlag; 2006:177-193.

43. Bortz J, Döring N: Forschungsmethoden und Evaluation für Human- und Sozialwissenschaftler. Berlin/Heidelberg: Springer-Verlag; 2002.

44. Lamnek S: Qualitative Sozialforschung. Lehrbuch. Psychologie Verlagsunion: Weinheim; 2005.

45. Steinke I: Gütekriterien qualitativer Forschung. In Qualitative Forschung Ein Handbuch. Edited by Flick U, Von Kardoff E, Steinke I. Reinbek: Rowohlt Verlag; 2000:319-331.

46. Seale C: The Quality of Qualitative Research. London: SAGE Publications Ltd.; 1999

47. Bourgeault I, Dingwall R, De Vries R: Qualitative Methods in Health Research. London: SAGE Publications Ltd.; 2011.

48. Green J, Thorogood N: Qualitative Methods for Health Research. 2nd edition. London: SAGE Publications Ltd.; 2009.

49. Bergman MM: Mixed Methods Research. London: SAGE Publications Ltd.; 2009

50. Denzin N, Lincoln YS: The SAGE Handbook of Qualitative Research. 4th edition. London: SAGE Publications Ltd.; 2012.

51. Inthorn J: Quantitative und qualitative Forschungsmethoden in den Sozialwissenschaften. Eine philosophische Analyse der Argumente des Methodenstreits. Munich: PhD thesis. Munich School of Philosophy; 2010.

52. Taylor HA, Hull SC, Kass NE: Qualitative Methods. In Methods in Medical Ethics. 2nd edition. Edited by Sugarman J, Sulmasy DP. Washington: Georgetown University Press; 2010:193-214.

53. Pearlman RA, Starks HE: Quantitative Surveys. In Methods in Medical Ethics. 2nd edition. Edited by Sugarman J, Sulmasy DP. Washington: Georgetown University Press; 2010:233-250.

54. Hurst S: What 'empirical turn in bioethics'? Bioethics 2010, 24:439-444.

55. Salloch S, Schildmann J, Vollmann J: Empirical research in medical ethics: How conceptual accounts on normative-empirical collaboration may improve research practice. BMC Med Ethics 2012, 13:5.

56. Forschungsgemeinschaft D: Sicherung guter wissenschaftlicher Praxis. Denkschrift. Wiley-VCH: Weinheim; 1998.

57. Fuchs M: Gute wissenschaftliche Praxis. In Forschungsethik. Eine Einführung. Edited by Fuchs M, Heinemann T, Heinrichs B, Hübner D, Kipper J, Rottländer K, Runkel T, Spranger TM, Vermeulen V, Völker-Albert M. Stuttgart/Weimar: J.B. Metzler; 2010:41-55.
58. Emanuel EJ, Wendler D, Grady C: An ethical framework for biomedical research. In The Oxford Textbook of Clinical Research Ethics. Edited by Emanuel EJ, Grady C, Crouch RA, Lie RK, Miller FG, Wendler D. New York: Oxford University Press; 2008:123-135.

59. Heinemann T: Forschung und Gesellschaft. In Forschungsethik. Eine Einführung. Edited by Fuchs M, Heinemann T, Heinrichs B, Hübner D, Kipper J, Rottländer K, Runkel T, Spranger TM, Vermeulen V, Völker-Albert M. Stuttgart/Weimar: J.B. Metzler; 2010:98-119.

60. Schünemann HJ, Wiercioch W, Etxeandia I, Falavigna M, Santesso N, Mustafa R, Ventresca V, Brignardello-Petersen R, Laisaar K-T, Kowalski S, Baldeh T, Zhang Y, Raid U, Neumann I, Norris SL, Thornton J, Harbour R, Treweek S, Guyatt G, Alonso-Coello P, Reinap M, Brožek J, Oxman A, AkI EA: Guidelines 2.0: systematic development of a comprehensive checklist for a successful guideline enterprise. CMAJ 2013. http://cebgrade.mcmaster.ca/ guidelinechecklistprintable.pdf.

61. Scottish Intercollegiate Guidelines Network: SIGN 50: A guideline developer's handbook. Revised edition 2011. Edinburgh. 2011. http://sign.ac.uk/guidelines/ fulltext/50/compchecklist.html.

62. Schulz KF, Altman DG, Moher D, CONSORT Group. CONSORT 2010 Statement: Updated Guidelines for Reporting Parallel Group Randomised Trials. PLoS Med 2010, 7(3):e1000251. http://www.consort-statement.org/ consort-statement/overview0/\#checklist.

63. Von Elm E, Altman DG, Egger M, Pocock SJ, Gøtzsche PC, Vandenbroucke JP: The Strengthening the Reporting of Observational Studies in Epidemiology (STROBE) statement: guidelines for reporting observational studies. PLoS Med 2007, 4:e296. http://www.strobestatement.org/fileadmin/Strobe/uploads/checklists/ STROBE_checklist_v4_combined.pdf.

64. Young JM, Solomon MJ: How to critically appraise an article. Nat Rev Gastroenterol Hepatol 2009, 6:82-91.

65. The Critical Appraisal Company. http://www.criticalappraisal.com.

66. Graumann S, Lindemann G: Medizin als gesellschaftliche Praxis, sozialwissenschaftliche Empirie und ethische Reflexion: ein Vorschlag für eine soziologisch aufgeklärte Medizinethik. Ethik Med 2009, 21:235-245.

67. Hirschauer S, Kalthoff H: Lindemann G (eds.): Theoretische Empirie. Zur Relevanz qualitativer Forschung. Frankfurt am Main. Berlin: Suhrkamp; 2008.

68. Kelle U: Integration qualitativer und quantitativer Methoden in der empirischen Sozialforschung. Theoretische Grundlagen und methodologische Konzepte, 2. ed. VS Verlag für Sozialwissenschaften: Wiesbaden; 2008.

69. De Vries R: How can we help? From "Sociology in" to "Sociology of" Bioethics. J Law Med Ethics 2003, 32(2):279-292.

70. Schicktanz S, Schweda M, Wynne B: The ethics of 'public understanding of ethics' - Why and how bioethics expertise should include public and patients' Voices. Med Health Care Philos 2011, 15(2):129-139.

71. Taylor C: Quellen des Selbst, Frankfurt am Main: Suhrkamp; 1994.

72. Anderson J: Neuro-Prosthetics, the Extended Mind, and Respect for Persons with Disability. In The Contingent Nature of Life. 39th edition. Edited by Düwell M, Rehmann-Sutter C, Mieth D. New York: International Library of Ethics, Law, and the New Medicine; 2008:259-274.

73. Khushf G: Why Bioethics needs the Philosophy of Medicine: Some Implications of Reflection on Concepts of Health and Disease. Theor Med 1997, 18:145-163.

74. Appiah KA: The ethics of identity. University Press: Princeton; 2005.

75. Strech D: Evidenz und Ethik. Kritische Analysen zur Evidenz-basierten Medizin und empirischen Ethik. Berlin: Lit Verlag; 2008

76. Weaver GR, Trevino LK: Normative and Empirical Buisness Ethics: Separation, Marriage of Convenience, or Marriage of Necessity? Bus Ethics Q 1994, 4(2):129-143.

77. Reiter-Theil S, Mertz M, Schürmann J, Stingelin Giles N, Meyer-Zehnder B: Evidence - competence - discourse: the theoretical framework of the multi-centre clinical ethics support project METAP. Bioethics 2011, 25(7):403-412

78. Leget C, Borry P, De Vries R: Nobody tosses a dwarf!The relation between the empirical and the normative reexamined. Bioethics 2009, 23:226-235.

79. Lenk H: Einführung in die Angewandte Ethik. Verantwortlichkeit und Gewissen. W. Kohlhammer GmbH: Stuttgart/Berlin/Köln; 1997.

80. Wöhlke S: The morality of giving and receiving living kidneys: Empirical findings on opinions of affected patients. In Public Engagement in Organ Donation. Edited by Schicktanz S. Randhawa. Lengerich: Pabst Science Publishers. in press. 
81. Ashcroft RE: Constructing empirical bioethics: Foucauldian reflections on the empirical turn in bioethics research. Health Care Anal 2003, 11:3-13.

82. Salloch S, Vollmann J, Schildmann J: Ethics by opinion poll? The functions of attitudes research for normative deliberations in medical ethics. J Med Ethics. doi:10.1136/medethics-2012-101253.

83. Parker M: Two concepts of empirical ethics. Bioethics 2009, 23(4):202-213.

84. Strech D, Synofzik M, Marckmann G: Systematic reviews of empirical bioethics. J Med Ethics 2008, 34:472-477.

85. Solbakk JH: Use and abuse of empirical knowledge in contemporary bioethics. A critical analysis of empirical arguments employed in the controversy surrounding studies of maternal-fetal HIV-transmission and HIV-prevention in developing countries. Med Health Care Philos 2004, 7:5-16.

86. Israel M, Hay I: Research Ethics for Social Scientists. London: Sage Publications; 2006

87. Beauchamp TL, Childress JF: Principles of Biomedical Ethics. 6th edition. New York: Oxford University Press; 2009.

88. Armstrong PW, Califf RM: Data and safety monitoring boards: academic credit where credit is due? JAMA 2013, 310(15):1563-1564

89. National Academy of Sciences: Committee on Ensuring the Utility and Integrity of Research Data in a Digital Age; Committee on Science, Engineering, and Public Policy (COSEPUP); Policy and Global Affairs (PGA); Institute of Medicine (IOM): Ensuring the Integrity, accessibility, and Stewardship of research data in the digital age. Washington, D.C: The National Academies Press; 2009. http://www.nap.edu/openbook.php?record_id=12615.

90. Faden RR, Beauchamp TL: A History and Theory of Informed Consent. Oxford: Oxford University Press; 1986.

91. Annas GJ, Grodin MA: The Nuremberg Code. In The Oxford Textbook of Clinical Research Ethics. Edited by Emanuel EJ, Grady C, Crouch RA, Lie RK, Miller FG, Wendler D. New York: Oxford University Press; 2008:136-140.

92. National Academy of Sciences, National Academy of Engineering: Committee on Science, Engineering, and Public Policy (COSEPUP); Institute of Medicine (IOM); Policy and Global Affairs (PGA): On being a scientist. A guide to responsible conduct in research. Thirdth edition. Washington, D.C: The National Academies Press; 2009. http://www.nap.edu/openbook.php? record_id=12192.

93. Institute of Medicine (IOM): Conflicts of Interest in Medical Research Education, and Practice. Washington D.C: National Academic Press; 2009.

94. European Medicines Agency (EMA): ICH Topic E6 (R1) Guideline for Good Clinical Practice. http://www.emea.europa.eu/docs/en_GB/document_library/ Scientific guideline/2009/09/WC500002874.pdf.

95. World Medical Association (WMA): WMA-Declaration of Helsinki - Ethical Principles for Medical Research Involving Human Subjects. http://www.wma. net/en/30publications/10policies/b3/.

96. German Psychological Society (DGP) and the Association of German Professional Psychologists (BDP): Ethical Principles of the German Psychological Society and the Association of German Professional Psychologists. http://www.bdp-verband.org/bdp/verband/clips/ethic.pdf.

97. Ethics Committee of the British Psychological Society: Code of Ethics and Conduct. Guidance. ; 2009. http://www.bps.org.uk/sites/default/files/ documents/code_of_ethics_and_conduct.pdf.

98. National Committees for Research Ethics in Norway: Guidelines for Research Ethics in the Social Sciences, Law and the Humanities. http://graduateschool. nd.edu/assets/21765 guidelinesresearchethicsinthesocialscienceslawhumanities.pdf.

99. Respect Project: RESPECT Code of Practice for Socio-Economic Research http://www.respectproject.org/code/respect_code.pdf.

100. Canadian Institutes of Health Research: Natural Sciences and Engineering Research Council of Canada, and Social Sciences and Humanities Research Council of Canada: Tri-Council Policy Statement: Ethical Conduct for Research Involving Humans. http://www.pre.ethics.gc.ca.
101. Jacoby L, Siminoff L: Empirical Methods for Bioethics. Oxford: A Primer. Elsevier JAl; 2008.

102. Miller FG, Wendler D: The relevance of empirical research in bioethics. Schizophr Bull 2006, 32:37-41.

103. Nilstun T, Melltorp G, Hermeren G: Surveys on attitudes to active euthanasia and the difficulty of drawing normative conclusions. Scand Public Health 2000, 28:111-116.

104. Strech D, Schildmann J: Quality of ethical guidelines and ethical content in clinical guidelines: the example of end-of-life decision-making. J Med Ethics 2011, 37(7):390-396.

doi:10.1186/1472-6939-15-17

Cite this article as: Mertz et al:: Research across the disciplines: a road map for quality criteria in empirical ethics research. BMC Medical Ethics 2014 15:17.

\section{Submit your next manuscript to BioMed Central and take full advantage of:}

- Convenient online submission

- Thorough peer review

- No space constraints or color figure charges

- Immediate publication on acceptance

- Inclusion in PubMed, CAS, Scopus and Google Scholar

- Research which is freely available for redistribution 